\title{
Cardiovascular comorbidities of atopic dermatitis: using National Health Insurance data in Korea
}

Hye Jung Jung, Dong Heon Lee $\mathbb{B}$, Mi Youn Park and Jiyoung Ahn* (i)

\begin{abstract}
Background: It is well known that atopic dermatitis (AD) is associated with other allergic diseases. Recentely, links to diseases other than allergic disease have also been actively studied. Among them, the results of studies regarding AD comorbidities, especially cardiovascular disease (CVD), have varied from country to country.

Objective: To analyze whether the risk of CVD is different between AD patients and healthy controls using Korean National Health Insurance Data.

Methods: We obtained data from 2005 to 2016 from the Korean National Health Insurance Research Database. Patients with one AD code and two AD-related tests codes were selected as AD patients, and age-and sex-matched controls to the AD patients were selected from among those without $A D$ (1:5). Each group was investigated for accompanying metabolic syndrome (which contains hypertension, type 2 diabetes, and hyperlipidemia) and CVD (angina, myocardial infarction, peripheral vascular disease, and stroke) using ICD 10 codes.

Results: The incidence of metabolic diseases and CVD were significantly different between the AD and control groups. Using multivariable Cox regression, differences were adjusted for sex, age, and other CVD and metabolic diseases. As a result, not only metabolic disease, but also the CVD risk of AD patients was significantly higher than that of the control group. Patients with AD had as significantly higher risk of hyperlipidemia (hazard ratio $[H R]=33.02$, $p<0.001)$, hypertension ( $H R=4.86, p<0.001)$, and type 2 diabetes $(H R=2.96, p<0.001)$. AD patients also had a higher risk of stroke ( $H R=10.61, p<0.001)$, myocardial infarction ( $H R=9.43, p<0.001)$, angina $(H R=5.99, p<0.001)$, and peripheral vascular disease $(H R=2.46, p<0.001)$. Besides hyperlipidemia, there was no difference in risk according to AD severity.
\end{abstract}

Conclusion: Patients with AD have a greater risk of CVD than those without AD.

Keywords: Atopic dermatitis, Comorbidities, Cardiovascular diseases, Metabolic syndrome

\section{Introduction}

Atopic dermatitis (AD) is one of the most common inflammatory diseases in medicine, associated with a broad patient burden of skin lesions, pruritus, and both allergic and non-allergic comorbidities. The link

*Correspondence: jiyoung.ahn@nmc.or.kr Department of Dermatology, National Medical Center, 245, Eulji-ro, Jung-gu, Seoul 04564, Republic of Korea between $\mathrm{AD}$ and other allergic diseases such as food allergies, allergic rhinitis, and asthma is well known [1]. Recently, in addition to allergic diseases, research has been conducted on the relationship between $\mathrm{AD}$ and other diseases such as depression, alopecia areata, inflammatory bowel disease, and cardiovascular disease (CVD) and metabolic syndrome [2].

Among them, the relationship between CVD, metabolic syndrome, and $\mathrm{AD}$ is interesting because it original author(s) and the source, provide a link to the Creative Commons licence, and indicate if changes were made. The images or other third party material in this article are included in the article's Creative Commons licence, unless indicated otherwise in a credit line to the material. If material is not included in the article's Creative Commons licence and your intended use is not permitted by statutory regulation or exceeds the permitted use, you will need to obtain permission directly from the copyright holder. To view a copy of this licence, visit http://creativecommons.org/licenses/by/4.0/. The Creative Commons Public Domain Dedication waiver (http://creativeco mmons.org/publicdomain/zero/1.0/) applies to the data made available in this article, unless otherwise stated in a credit line to the data. 
indicates that $\mathrm{AD}$ is an inflammatory disease beyond the skin and could threaten one's life.

Regarding this comorbidity, there are some differing results on the pathogenesis depending on the country and study. An explanation for these varying results may be that observational research is more difficult to interpret in contrast to laboratory-based studies because there is a tendency to use one data source and study design per study. Accordingly, several studies have been conducted with a cross-sectional, cohort, or population-based cohort study design for $A D$ comorbidity; and while cross-sectional studies provide information at just one point in time, cohort studies provide well described and longitudinal data [3]. No large-scale research about $\mathrm{AD}$ comorbidity has been done in Korea yet.

It is well known that psoriasis is related to CVD and metabolic syndrome and psoriasis is another common chronic inflammatory skin disease caused by immune dysregulation. It has already been confirmed that inflammatory mediators such as TNF- $\alpha$, IL-23, and IL-17 active in psoriasis promote metabolic disease or share similar pathways [4]. It has also been confirmed that treatment of psoriasis reduces CVD risk. For example, it has been reported that patients treated with inflammation using TNF- $\alpha$ inhibitors have a $21 \%$ lower risk of myocardial infarction (MI) than patients treated with topical agents or phototherapy [5].

Although specific cytokines or pathways are different, these two diseases can be related due to the immune dysregulation that is involved in $\mathrm{AD}$ development [6].

\section{Methods}

For the study, data satisfying the following conditions were extracted from the Korean National Health Insurance Research Database and used for analysis.

\section{AD patient group}

Before the study, the authors conducted a validation study. It is essential to find the most accurate screening criteria for $\mathrm{AD}$ patients among patients with $\mathrm{AD}$ diagnostic codes registered in the National Health Insurance Research Database. As a result, patients who had one of the $\mathrm{AD}$ diagnostic codes and underwent two AD-related tests were determined to be the most appropriate [7] and were selected. The target period was from 2005 to 2016. The AD diagnosis codes used were as follows: AD (L209.000.02, L209.000.01, L209.000, and L2088.000), adult AD (L2088.004), atopic neurodermatitis (L2080.000), childhood AD (L2083.003), chronic AD (L209.000.03), and infantile AD (L2088.002).

\section{AD severity classification}

AD was classified into clear, mild, moderate, and severe. Clear patients had a suitable diagnosis and test code but no prescriptions for drugs. Mild patients were prescribed topical steroids (TCSs) or calcineurin inhibitors (TCIs), or antihistamine agents. Moderate patients were defined as patients using TCS or TCI with antihistamine agents, and severe patients were defined as patients using systemic immune modulators.

\section{Control group}

The control group was selected by matching patients in age and sex to the $\mathrm{AD}$ patient group among hemorrhoidectomy patients without $\mathrm{AD}$ diagnostic codes. The target period was the same as that of the patient group, and the ratio of the patient and control groups was 1: 5 .

\section{CVD and metabolic syndrome}

Both patient and control groups were investigated for hypertension (HT), diabetes mellitus (DM), and hyperlipidemia among metabolic syndromes, and angina, MI, peripheral vascular disease (PVD), and stroke among CVD. The washout period was set to 2008. From 2009 to 2016, it was determined that the patient had the disease only if they were prescribed medication twice or more in an outpatient setting or hospitalized more than once. The data from the patient group were used only after the onset of $\mathrm{AD}$, and the data from the control group were used only after hemorrhoidectomy. We adjusted for age and sex for each outcome, and we additionally adjusted for each of the other 6 outcomes (e.g., for the analysis of HT, we additionally adjusted for DM, hyperlipidemia, angina, MI, PVD, and stroke), as these cardiovascular outcomes are correlated with each other. The ICD 10 codes used were as follows: I20 for angina; I21, I22, and I23 for MI; I70,I71, I72, and I73 for PVD; and I63 and I64 for stroke.

\section{Statistical analysis}

A Mann-Whitney test was used for frequency analysis. We used a multivariable Cox regression model to calculate the multivariable-adjusted hazard ratios (HRs) and 95\% confidence intervals (CIs) between AD and subsequent HT, DM, hyperlipidemia, angina, MI, PVD, and stroke. Statistical analyses were performed using SAS (Version 9.4, SAS Institute, Cary, NC), and the significance level was set at $\mathrm{p}<0.05$. 


\section{Results}

\section{Patient demographics}

The total number of patients was 2,780,356 (49.6\% male and $50.4 \%$ female). The largest proportion of patients were between 10 to 20 years old (38.5\%). According to the severity classification, clear, mild, moderate, and severe cases accounted for 32.9\% (49.8\% male and $50.2 \%$ female), $24 \%$ ( $49.2 \%$ male and $50.8 \%$ female), $2.1 \%$ (50.0\% male and 50.0\% female), and $41 \%$ (49.7\% male and $50.3 \%$ female), respectively (Table 1 ).

\section{Trend analysis in the number of atopic patients by year}

The total number of AD patients was 1,56,883 in 2005 and increased year by year thereafter to $2,85,468$ in 2016. This increase was statistically significant. For each subgroup, those under 10 years and over 30 years increased significantly, and severe $\mathrm{AD}$ increased regardless of sex and age (Fig. 1).

\section{Frequency analysis}

The proportion of AD patients among $\mathrm{HT}$ patients was $19.19 \%$, and $16.81 \%$ among those without HT $(\mathrm{p}<0.0001)$. The proportion of AD patients among DM, hyperlipidemia, angina, MI, PVD, and stroke was $20.02 \%, 23.86 \%, 27.16 \%, 24.7 \%, 18.94 \%$, and $19.12 \%$, respectively. The proportion of $\mathrm{AD}$ among those without DM, hyperlipidemia, angina, MI, PVD, and stroke was $16.85 \%, 15.94 \%, 16.84 \%, 16.85 \%, 16.85 \%$, and $16.85 \%$, respectively. Statistically significant differences were seen in DM, hyperlipidemia, angina, MI, and stroke except PVD $(\mathrm{p}=0.1345)$. The results based on severity are as follows: the proportion of severe $\mathrm{AD}$ in HT, type 2 DM, hyperlipidemia, angina, MI, PVD, and stroke patients was $18.57 \%, 19.28 \%, 22.67 \%, 26.48 \%$, $23.71 \%, 18.38 \%, 18.39 \%$, respectively. The proportion of severe AD among those who did not have HT, type 2 DM, hyperlipidemia, angina, MI, PVD, and stroke was $14.94 \%, 14.99 \%, 14 \%, 14.99 \%, 15 \%, 15 \%$, and $15 \%$, respectively. The difference in proportions was statistically significant (Tables 2 and 3 ).

\section{Multivariable Cox regression analysis}

Using a multivariable Cox regression model, differences were adjusted for sex, age, and other CVD and metabolic diseases. As a result, the metabolic disease and CVD risk of AD patients was significantly higher than that of the control group. Patients with AD had a significantly higher risk of hyperlipidemia $(H R=33.02$, $\mathrm{p}<0.001)$, HT $(\mathrm{HR}=4.86, \mathrm{p}<0.001)$, and type $2 \mathrm{DM}$ $(\mathrm{HR}=2.96, \mathrm{p}<0.001)$. AD patients also had a higher risk of stroke $(H R=10.61, p<0.001)$, MI $(H R=9.43$,
Table 1 Patient demographics

\begin{tabular}{|c|c|c|c|}
\hline & & $N$ & $\%$ \\
\hline \multirow[t]{11}{*}{ Total } & Total & $27,80,356$ & 100 \\
\hline & Male & $13,79,336$ & 49.6 \\
\hline & Female & $14,01,020$ & 50.4 \\
\hline & Under 10 & $7,20,298$ & 25.9 \\
\hline & $10 \mathrm{~s}$ & $1,071,286$ & 38.5 \\
\hline & $20 \mathrm{~s}$ & $4,51,595$ & 16.2 \\
\hline & $30 \mathrm{~s}$ & $2,57,407$ & 9.3 \\
\hline & $40 \mathrm{~s}$ & $1,32,198$ & 4.8 \\
\hline & $50 \mathrm{~s}$ & 77,637 & 2.8 \\
\hline & $60 \mathrm{~s}$ & 43,781 & 1.6 \\
\hline & Over 70 & 26,154 & 0.9 \\
\hline \multirow[t]{11}{*}{ Clear } & Total & $9,13,415$ & \\
\hline & Male & $4,54,539$ & 49.8 \\
\hline & Female & $4,58,876$ & 50.2 \\
\hline & Under 10 & $3,03,988$ & 33.3 \\
\hline & $10 \mathrm{~s}$ & $3,45,565$ & 37.8 \\
\hline & $20 \mathrm{~s}$ & $1,16,756$ & 12.8 \\
\hline & $30 s$ & 70,086 & 7.7 \\
\hline & $40 \mathrm{~s}$ & 36,491 & 4.0 \\
\hline & $50 \mathrm{~s}$ & 22,446 & 2.5 \\
\hline & $60 \mathrm{~s}$ & 11,719 & 1.3 \\
\hline & Over 70 & 6364 & 0.7 \\
\hline \multirow[t]{11}{*}{ Mild } & Total & $6,67,895$ & \\
\hline & Male & $3,28,617$ & 49.2 \\
\hline & Female & $3,39,278$ & 50.8 \\
\hline & Under 10 & $1,45,217$ & 21.7 \\
\hline & $10 \mathrm{~s}$ & $2,93,275$ & 43.9 \\
\hline & $20 \mathrm{~s}$ & $1,12,238$ & 16.8 \\
\hline & $30 \mathrm{~s}$ & 55,581 & 8.3 \\
\hline & $40 \mathrm{~s}$ & 29,353 & 4.4 \\
\hline & $50 \mathrm{~s}$ & 16,338 & 2.4 \\
\hline & $60 s$ & 9653 & 1.4 \\
\hline & Over 70 & 6240 & 0.9 \\
\hline \multirow[t]{11}{*}{ Moderate } & Total & 58,148 & \\
\hline & Male & 29,049 & 50.0 \\
\hline & Female & 29,099 & 50.0 \\
\hline & Under 10 & 13,486 & 23.2 \\
\hline & $10 \mathrm{~s}$ & 20,939 & 36.0 \\
\hline & $20 \mathrm{~s}$ & 12,702 & 21.8 \\
\hline & $30 \mathrm{~s}$ & 6758 & 11.6 \\
\hline & $40 \mathrm{~s}$ & 2547 & 4.4 \\
\hline & $50 \mathrm{~s}$ & 836 & 1.4 \\
\hline & $60 s$ & 481 & 0.8 \\
\hline & Over 70 & 399 & 0.7 \\
\hline
\end{tabular}


Table 1 (continued)

\begin{tabular}{llll}
\hline & N & $\%$ \\
\hline Severe & Total & $11,40,898$ & \\
& Male & $5,67,131$ & 49.7 \\
& Female & $5,73,767$ & 50.3 \\
Under 10 & $2,57,607$ & 22.6 \\
$10 \mathrm{~s}$ & $4,11,507$ & 36.1 \\
$20 \mathrm{~s}$ & $2,09,899$ & 18.4 \\
$30 \mathrm{~s}$ & $1,24,982$ & 11.0 \\
& $40 \mathrm{~s}$ & 63,807 & 5.6 \\
$50 \mathrm{~s}$ & 38,017 & 3.3 \\
$60 \mathrm{~s}$ & 21,928 & 1.9 \\
& Over 70 & 13,151 & 1.2 \\
\hline
\end{tabular}

$\mathrm{p}<0.001)$, angina $(\mathrm{HR}=5.99, \mathrm{p}<0.001)$ and $\mathrm{PVD}$ $(\mathrm{HR}=2.46, \mathrm{p}<0.001)$ (Table 4 and Fig. 2).

\section{Multivariable Cox regression analysis according to $A D$ severity}

Differences in metabolic diseases or CVD according to $\mathrm{AD}$ severity were analyzed. As the severity of AD increased, the risk of hyperlipidemia increased $(\mathrm{HR}=14.93,24.05,29.04$, and 34.35 in clear, mild, moderate, and severe cases) $(\mathrm{p}<0.001)$. However, in other diseases, a consistent increase in risk according to the $\mathrm{AD}$ severity could not be confirmed (Table 4 and Fig. 3).

\section{Discussion}

There are several studies on the relationship between AD and CVD. When the link between the two diseases was first noticed, studies mainly focused on establishing the existence of the link. Initially, results were often reported that the two diseases were not related [8-13]. In 2017, Standl et al. [9] investigated the relationship between AD and CVD in three groups of cohorts and whether they had genetic risk factors of CVD. As a result, the risk of angina, HT, and PVD was slightly increased in only one cohort, and the risks of other diseases, such as MI and stroke, were not different. The other two cohorts showed no difference in all diseases. In addition, differences in genetic the risk factors of CVD had not been identified. In a systemic review and meta-analysis conducted by Thyssen et al. [10] AD was only related to angina but not type $2 \mathrm{DM}, \mathrm{HT}$, stroke, and MI.

In 2017, the Council of the International Eczema of Council reviewed the results of previous studies and argued that $\mathrm{AD}$ and cardiovascular morbidities are related [14]. In addition, in a population-based matched cohort study conducted in 2018, the risk of CVD in $\mathrm{AD}$ patients was increased, which was proportional to the severity of AD [15]. Subsequently, the relationship

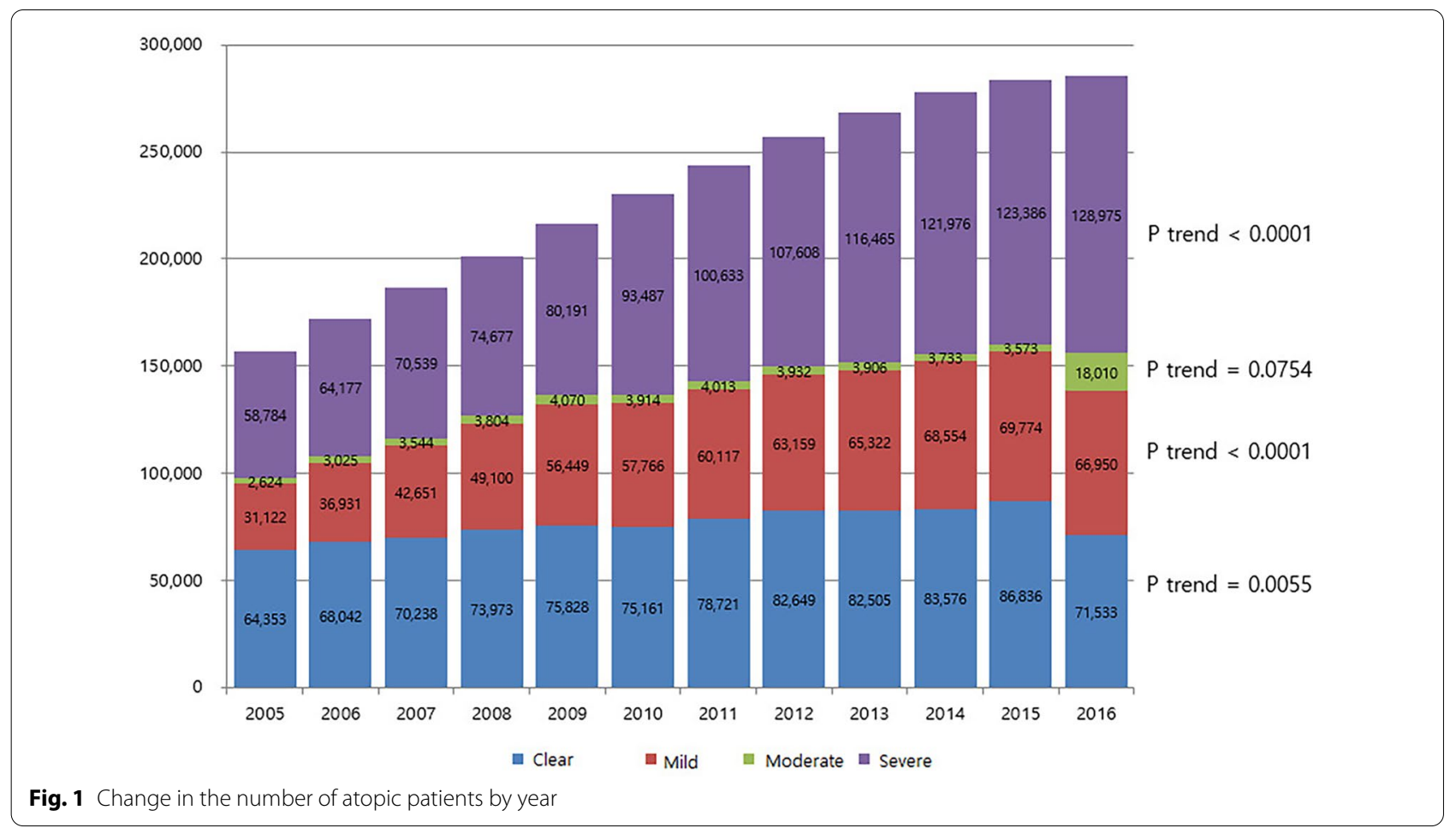


Table 2 Frequency analysis of metabolic disorders

\begin{tabular}{|c|c|c|c|c|}
\hline & & Without & With & p-Value \\
\hline \multicolumn{5}{|c|}{ Hypertension } \\
\hline$A D$ & & $2,87,416(16.81 \%)$ & 3580 (19.19\%) & $<0.0001$ \\
\hline \multirow[t]{2}{*}{ Controls } & & $14,22,040$ (83.19\%) & $15,072(80.81 \%)$ & \\
\hline & Controls & $14,22,040$ (83.19\%) & $15,072(80.81 \%)$ & $<0.0001$ \\
\hline \multirow[t]{4}{*}{$A D$} & Clear & $6996(0.41 \%)$ & $9(0.05 \%)$ & \\
\hline & Mild & $20,262(1.19 \%)$ & $85(0.46 \%)$ & \\
\hline & Moderate & $4783(0.28 \%)$ & $22(0.12 \%)$ & \\
\hline & Severe & $2,55,375(14.94 \%)$ & 3464 (18.57\%) & \\
\hline \multicolumn{5}{|c|}{ Type 2 diabetes } \\
\hline$A D$ & & $2,92,987(16.85 \%)$ & $321(20.02 \%)$ & 0.0007 \\
\hline \multirow[t]{2}{*}{ Controls } & & $14,46,286(83.15 \%)$ & $1282(79.98 \%)$ & \\
\hline & Controls & $14,46,286(83.15 \%)$ & 1282 (79.98\%) & $<0.0001$ \\
\hline \multirow[t]{4}{*}{$A D$} & Clear & 7014 (0.4\%) & $0(0 \%)$ & \\
\hline & Mild & $20,401(1.17 \%)$ & $10(0.62 \%)$ & \\
\hline & Moderate & $4824(0.28 \%)$ & $2(0.12 \%)$ & \\
\hline & Severe & $2,60,748$ (14.99\%) & 309 (19.28\%) & \\
\hline \multicolumn{5}{|c|}{ Hyperlipidemia } \\
\hline$A D$ & & 2,46,067 (15.94\%) & $43,746(23.86 \%)$ & $<0.0001$ \\
\hline \multirow[t]{2}{*}{ Controls } & & $12,97,450(84.06 \%)$ & $1,39,612(76.14 \%)$ & \\
\hline & Controls & $12,97,450(84.06 \%)$ & $1,39,612(76.14 \%)$ & $<0.0001$ \\
\hline \multirow[t]{4}{*}{$A D$} & Clear & $6741(0.44 \%)$ & $264(0.14 \%)$ & \\
\hline & Mild & $18,852(1.22 \%)$ & $1465(0.8 \%)$ & \\
\hline & Moderate & $4357(0.28 \%)$ & $448(0.24 \%)$ & \\
\hline & Severe & $2,16,117(14 \%)$ & $41,569(22.67 \%)$ & \\
\hline
\end{tabular}

between the two diseases has been steadily reported [4, 14-25].

Recent research has been actively conducted on the mechanism of $\mathrm{AD}$ affecting $\mathrm{CVD}$, in addition to elucidating their relationship. The results of how diseases affect each other can be roughly divided into two categories: direct or indirect.. Direct interaction appears primarily in the results of studies conducted in some of the United States and Asia [11, 16, 24, 26]. It is an opinion that immune dysregulation of AD directly acts as a factor to increase CVD risk. In this case, even if confounding factors are adjusted, the difference in risk is maintained [21, 27, 28]. Indirect interaction appears in results obtained mainly in Denmark, a proxy for Europe [10, 19, 20, 25, 29]. AD increases other risk factors of CVD such as sleep disturbance, depression, oral corticosteroid use, smoking, obesity, type 2 DM, HT, hyperlipidemia, and low physical activity. In this case, if the other factors are corrected, the difference in risk disappears $[10,29]$. However, direct and indirect interactions are not always clearly distinguished. In a cross-sectional US population-based study conducted by Silverberg [17] in 2018, moderate to severe AD showed direct effects on DM and obesity. Additionally,
Table3 Frequency analysis of CVD

\begin{tabular}{|c|c|c|c|c|}
\hline & & Without & With & p-Value \\
\hline \multicolumn{5}{|l|}{ Angina } \\
\hline$A D$ & & $2,93,894(16.84 \%)$ & $239(27.16 \%)$ & $<0.0001$ \\
\hline \multirow[t]{2}{*}{ Controls } & & $14,50,937(83.16 \%)$ & $641(72.84 \%)$ & \\
\hline & Controls & $14,50,937(83.16 \%)$ & $641(72.84 \%)$ & $<0.0001$ \\
\hline \multirow[t]{4}{*}{$A D$} & Clear & $7014(0.4 \%)$ & $0(0 \%)$ & \\
\hline & Mild & $20,425(1.17 \%)$ & $4(0.45 \%)$ & \\
\hline & Moderate & $4827(0.28 \%)$ & $2(0.23 \%)$ & \\
\hline & Severe & $2,61,628(14.99 \%)$ & $233(26.48 \%)$ & \\
\hline \multicolumn{5}{|c|}{ Myocardial infarction } \\
\hline$A D$ & & $2,94,340(16.85 \%)$ & $163(24.77 \%)$ & $<0.0001$ \\
\hline \multirow[t]{2}{*}{ Controls } & & $14,52,273(83.15 \%)$ & $495(75.23 \%)$ & \\
\hline & Controls & $14,52,273(83.15 \%)$ & $495(75.23 \%)$ & $<0.0001$ \\
\hline \multirow[t]{4}{*}{$A D$} & Clear & $7015(0.4 \%)$ & $0(0 \%)$ & \\
\hline & Mild & $20,427(1.17 \%)$ & $6(0.91 \%)$ & \\
\hline & Moderate & $4830(0.28 \%)$ & $1(0.15 \%)$ & \\
\hline & Severe & $2,62,068(15 \%)$ & $156(23.71 \%)$ & \\
\hline \multicolumn{5}{|c|}{ Peripheral vascular diseases } \\
\hline$A D$ & & $2,93,968(16.85 \%)$ & $136(18.94 \%)$ & 0.1345 \\
\hline \multirow[t]{2}{*}{ Controls } & & $14,50,617(83.15 \%)$ & $582(81.06 \%)$ & \\
\hline & Controls & $14,50,617(83.15 \%)$ & $582(81.06 \%)$ & 0.0086 \\
\hline \multirow[t]{4}{*}{$A D$} & Clear & $7016(0.4 \%)$ & $0(0 \%)$ & \\
\hline & Mild & $20,423(1.17 \%)$ & $2(0.28 \%)$ & \\
\hline & Moderate & $4828(0.28 \%)$ & $2(0.28 \%)$ & \\
\hline & Severe & $2,61,701(15 \%)$ & $132(18.38 \%)$ & \\
\hline \multicolumn{5}{|l|}{ Stroke } \\
\hline$A D$ & & $2,94,139(16.85 \%)$ & $290(19.12 \%)$ & 0.0186 \\
\hline \multirow[t]{2}{*}{ Controls } & & $14,51,198(83.15 \%)$ & 1227 (80.88\%) & \\
\hline & Controls & $14,51,198(83.15 \%)$ & 1227 (80.88\%) & 0.0001 \\
\hline \multirow[t]{4}{*}{$A D$} & Clear & 7014 (0.4\%) & $2(0.13 \%)$ & \\
\hline & Mild & $20,427(1.17 \%)$ & $7(0.46 \%)$ & \\
\hline & Moderate & $4830(0.28 \%)$ & $2(0.13 \%)$ & \\
\hline & Severe & $2,61,868(15 \%)$ & 279 (18.39\%) & \\
\hline
\end{tabular}

it was confirmed that $\mathrm{AD}$ has indirect effects on high blood pressure and heart disease.

The results of our study confirmed that $\mathrm{AD}$ is associated with CVD after adjusting for other variables. Namely, when analyzing the association between AD and each disease, the difference from the control group was statistically significant even though corrections were made for other metabolic diseases or CVD, indicating that $\mathrm{AD}$ directly affects CVD and metabolic disease.

In particular, the positive correlation between CVD risk and the severity AD provides the strongest evidence for this relation. Recently, there have been reports of increased markers or similar pathways that commonly act in AD and CVD $[28,29]$. They are likely 
Table 4 Multivariable Cox regression analysis

\begin{tabular}{|c|c|c|c|c|c|}
\hline & & $\mathrm{HR}$ & $\mathrm{Cl}$ & & $\mathbf{P}$ \\
\hline \multirow[t]{5}{*}{$\mathrm{HT}$} & Total & 4.86 & 4.65 & 5.09 & $<0.0001$ \\
\hline & Clear & 2.61 & 1.36 & 5.02 & 0.004 \\
\hline & Mild & 4.62 & 3.73 & 5.72 & $<0.0001$ \\
\hline & Moderate & 4.61 & 3.03 & 7.02 & $<0.0001$ \\
\hline & Severe & 4.88 & 4.67 & 5.11 & $<0.0001$ \\
\hline \multirow[t]{5}{*}{ Type 2 DM } & Total & 2.96 & 2.56 & 3.41 & $<0.0001$ \\
\hline & Clear & 0.00 & 0.00 & 0.00 & 0.937 \\
\hline & Mild & 4.01 & 2.14 & 7.50 & $<0.0001$ \\
\hline & Moderate & 3.27 & 0.82 & 13.11 & 0.0948 \\
\hline & Severe & 2.94 & 2.54 & 3.39 & $<0.0001$ \\
\hline \multirow[t]{5}{*}{ Hyperlipidemia } & Total & 33.02 & 32.37 & 33.69 & $<0.0001$ \\
\hline & Clear & 14.93 & 13.22 & 16.85 & $<0.0001$ \\
\hline & Mild & 24.05 & 22.80 & 25.38 & $<0.0001$ \\
\hline & Moderate & 29.04 & 26.44 & 31.90 & $<0.0001$ \\
\hline & Severe & 34.35 & 33.66 & 35.06 & $<0.0001$ \\
\hline \multirow[t]{5}{*}{ Angina } & Total & 5.99 & 4.96 & 7.25 & $<0.0001$ \\
\hline & Clear & 0.00 & 0.00 & 0.00 & 0.9434 \\
\hline & Mild & 2.88 & 1.07 & 7.75 & 0.0365 \\
\hline & Moderate & 6.49 & 1.61 & 26.18 & 0.0085 \\
\hline & Severe & 6.16 & 5.09 & 7.47 & $<0.0001$ \\
\hline \multirow[t]{5}{*}{$\mathrm{Ml}$} & Total & 9.43 & 7.28 & 12.20 & $<0.0001$ \\
\hline & Clear & 0.00 & 0.00 & 0.00 & 0.9408 \\
\hline & Mild & 5.50 & 2.41 & 12.57 & $<.0001$ \\
\hline & Moderate & 3.92 & 0.55 & 28.15 & 0.1743 \\
\hline & Severe & 10.13 & 7.79 & 13.17 & $<.0001$ \\
\hline \multirow[t]{5}{*}{ PVD } & Total & 2.46 & 2.00 & 3.03 & $<0.0001$ \\
\hline & Clear & 0.00 & 0.00 & 0.00 & 0.9556 \\
\hline & Mild & 1.44 & 0.36 & 5.79 & 0.6082 \\
\hline & Moderate & 6.41 & 1.59 & 25.79 & 0.0089 \\
\hline & Severe & 2.48 & 2.01 & 3.05 & $<.0001$ \\
\hline \multirow[t]{5}{*}{ Stroke } & Total & 10.61 & 8.65 & 13.03 & $<0.0001$ \\
\hline & Clear & 18.20 & 4.52 & 73.20 & $<0.0001$ \\
\hline & Mild & 10.35 & 4.85 & 22.08 & $<0.0001$ \\
\hline & Moderate & 12.72 & 3.15 & 51.35 & 0.0004 \\
\hline & Severe & 10.56 & 8.59 & 12.98 & $<0.0001$ \\
\hline
\end{tabular}

to serve as the basis for direct associations between $\mathrm{AD}$ and CVD. It has been found that $\mathrm{AD}$ patients have increased levels of markers of atherosclerosis including fractalkine/CX3CL1, CCL8, M-CSF, and HGF, as well as increased levels of mediators of atherosclerosis such as E-selectin or PI3/elafin, CCL17, and IL-16, which are proportional to SCORAD [27]. In addition, it has been reported that $A D$ patients over the age of 60 have increased atherosclerosis markers such as CCL4, CCL7, and SORT1, cardiovascular risk markers (GDF15, MPO, ST2), and factors related to cell adhesion or apoptosis compared to young $\mathrm{AD}$ patients healthy indivisuals of the same age [28].

Meanwhile, there are many reasons for the heterogeneity of results regarding $\mathrm{AD}$ and its comorbidities. First, there are differences in the way $\mathrm{AD}$ is diagnosed. For example, AD patients may be selected by looking at previous medical records or through questionnaires. However, depending on the diagnostic method, AD diagnosis may not be accurate. One study obtained data through three types of questionnaires, and then $\mathrm{AD}$ and obesity were diagnosed. When comparing the diagnosis by the three questionnaires, the results were inconsistent [30]. In addition, the accuracy of AD diagnosis has been controversial when using registered ICD10 codes as in this study. This is because the accuracy may vary depending on what criteria are used and who performs the diagnosis. This study is meaningful in that it confirmed the accuracy of diagnosis in advance through validation.

Second, research methods are also very diverse, such as cross-sectional, population-based cohorts, or patient cohort studies [3]. In 2019, Ascotte et al. [23] conducted a systemic review and meta-analysis. They analyzed the study subjects by dividing it into cross-sectional and longitudinal cohort studies. In addition, it was analyzed according to the severity of AD. The cross-sectional study showed heterogenous results without any relationship between the diseases. In the cohort study, AD patients had a higher risk of MI, ischemic stroke, angina, and heart failure. In this study, it was found that the risk of CVD increased with the severity of AD. Dermatoepidemiologic studies include cross-sectional studies, routinely collected data, case control studies, population-based cohorts, patient cohorts, and interventions. More reliable results can be obtained by going to interventions in cross-sectional studies. In such large-scale studies, it is not easy to conduct patient cohorts or intervention studies. Our study is a population-based cohort study which can obtained relatively good results using well described longitudinal data [3].

In addition to the above two reasons, the types of diseases to be investigated and confounding factors differ slightly from study to study. Besides depending on the severity of $\mathrm{AD}$, the effect on comorbidities may vary. Most studies have not classified subjects according to severity, and even if classified, the criteria are not uniform.

The results of this study have various implications. First, the steady increase in AD was confirmed in the results of this study. Among them, the increase in $\mathrm{AD}$ over 30 years of age indicated that the study of systemic diseases that occur mainly in adults, such as CVD, is crucial for AD research. In addition, an increase in severe 

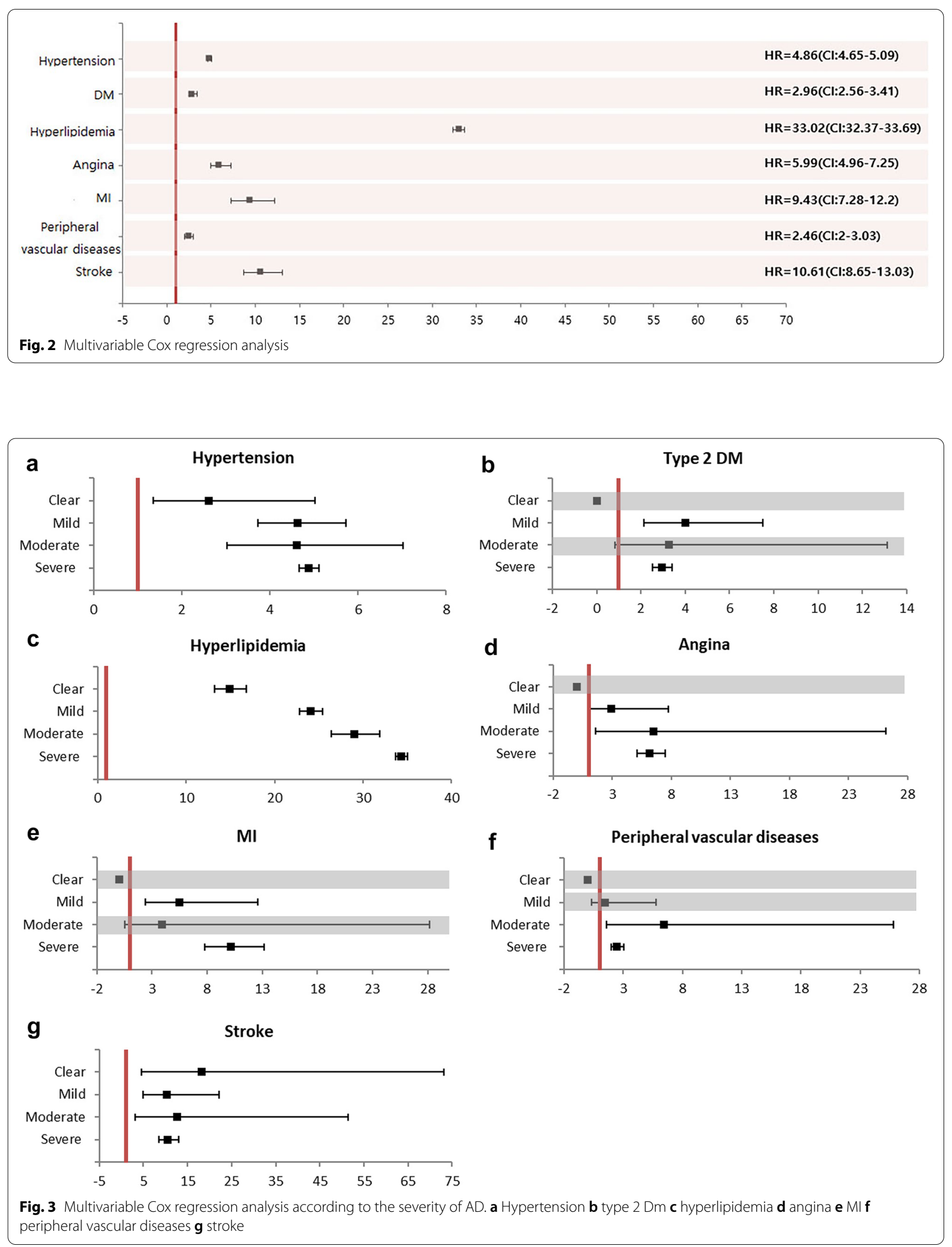
AD should also be noted. If the increase in comorbidities increases according to the severity, more active treatment is required. There have been only a few results from Taiwan in Asian studies, and the results from Koreans have been added to compare the differences among Asians.

A limitation of this study is that some factors important to CVD have not been adjusted for. Adjustments were made for age and sex, metabolic disorders, and other CVDs, but not for education level, physical activities, medication, obesity (body mass index), smoking, and alcohol intake. Another limitation is that it is impossible to accurately determine the causal relationship over time due to the study design, and there may be cases where an incident occurs, which is a problem that most studies have in common. Accordingly, a wellplanned longitudinal prospective cohort study should be conducted to draw a more accurate conclusion.

\section{Conclusion}

Atopic dermatitis (AD) is one of the most common inflammatory skin disease. Recently, in addition to allergic diseases, research has been conducted on the relationship between $\mathrm{AD}$ and other diseases especially cardiovascular disease (CVD) and metabolic syndrome. We analyzed whether the risk of CVD is different between $\mathrm{AD}$ patients and healthy controls using Korean National Health Insurance Data. As a result, not only metabolic disease, but also the CVD risk of AD patients was significantly higher than that of the control group. Patients with $\mathrm{AD}$ had as significantly higher risk of hyperlipidemia, hypertension, and type 2 diabetes. AD patients also had a higher risk of stroke, myocardial infarction, angina, and peripheral vascular disease. A well-planned longitudinal prospective cohort study should be conducted to draw a more accurate conclusion.

\section{Acknowledgements}

None.

\section{Authors' contributions}

HJJ collected scientific data and wrote the manuscript. DHL edited the manuscript. MYP reviewed and revised the manuscript. JA was the supervising author who conceived the idea and designed the study. All authors read and approved the final manuscript.

\section{Funding}

None.

Availability of data and materials

Not applicable.

\section{Declarations}

Ethics approval and consent to participate

This study was approved by the institutional review board of National Medical Center.
Consent for publication

Informed consent was obtained from the patient.

\section{Competing interests}

The authors have no competing interests.

Received: 15 December 2020 Accepted: 24 August 2021

Published online: 22 September 2021

\section{References}

1. Oliveira C, Torres T. More than skin deep: the systemic nature of atopic dermatitis. Eur J Dermatol. 2019;29:205-8.

2. Narla S, Silverberg J. Association between atopic dermatitis and autoimmune disorders in US adults and children: a cross-sectional study. J Am Acad Dermatol. 2019;80:382-9.

3. Nijsten T. Atopic dermatitis and comorbidities: added value of comprehensive dermatoepidemiology. J Invest Dermatol. 2017;137:1009-11.

4. Paller A, Jaworski JC, Simpson EL, Boguniewicz M, Russell JJ, Block JK, et al. Major comorbidities of atopic dermatitis: beyond allergic disorders. Am J Clin Dermatol. 2018;19:821-38.

5. Wu JJ, Poon KYT, Channual JC, Shen AYJ. Association between tumor necrosis factor inhibitor therapy and myocardial infarction risk in patients with psoriasis. Arch Dermatol. 2012;148:1244-50.

6. Furue M, Kadono T. "Inflammatory skin march" in atopic dermatitis and psoriasis. Inflamm Res. 2017;66:833-42.

7. Jung HJ, Lee DH, Jang DH, Lee Jl, Bae JY, Park MY, et al. P018 : Validation study to accurately identify patients with atopic dermatitis in the national health insurance data in Korea. Korean Dermatological Association The 71st Autumn Meeting. 2020;72:386.

8. Drucker AM, Qureshi AA, Dummer TJB, Parker L, Li WQ. Atopic dermatitis and risk of hypertension, type 2 diabetes, myocardial infarction and stroke in a cross-sectional analysis from the Canadian Partnership for Tomorrow Project. Br J Dermatol. 2017;177:1043-51.

9. Standl M, Tesch F, Baurecht H, Rodriguez E, Muller-Nurasyid M, Gieger C, et al. Association of atopic dermatitis with cardiovascular risk factors and diseases. J Invest Dermatol. 2017;137:1074-81.

10. Thyssen JP, Halling-Overgaard AS, Andersen YMF, Gislason G, Skov L, Egeberg A. The association with cardiovascular disease and type 2 diabetes in adults with atopic dermatitis: a systematic review and metaanalysis. Br J Dermatol. 2018;178:1272-9.

11. Andersen YMF, Egeberg A, Gislason GH, Skov L, Knop FK, Thyssen JP. Adult atopic dermatitis and the risk of type 2 diabetes. J Allergy Clin Immunol. 2017:139:1057-9.

12. Treudler R, Zeynalova S, Walther F, Engel C, Simon JC. Atopic dermatitis is associated with autoimmune but not with cardiovascular comorbidities in a random sample of the general population in Leipzig Germany. J Eur Acad Dermatol Venereol. 2018;32:e44-6.

13. Jachiet M, Nosbaum A, Staumont-Sallé D, Seneschal J, Viguier M, Soria A, et al. Low cardiovascular risk and poor quality of life associated with tobacco use and skin infections in adult atopic dermatitis: result of a French multicenter study. J Eur Acad Dermatol Venereol. 2019:33:e451-453.

14. Brunner PM, Silverberg Jl, Guttman-Yassky E, Paller AS, Kabashima K, Amagai $M$, et al. Increasing comorbidities suggest that atopic dermatitis is a systemic disorder. J Invest Dermatol. 2017;137:18-25.

15. Silverwood RJ, Forbes HJ, Abuabara K, Ascott A, Schmidt M, Schmidt SAJ, et al. Severe and predominantly active atopic eczema in adulthood and long term risk of cardiovascular disease: population based cohort study. BMJ. 2018. https://doi.org/10.1136/bmj.k1786.

16. Silverberg J. Association between adult atopic dermatitis, cardiovascular disease, and increased heart attacks in three population-based studies. Allergy. 2015;70:1300-8.

17. Silverberg Jl, Gelfand JM, Margolis DJ, Boguniewicz M, Fonacier L, Grayson $\mathrm{MH}$, et al. Association of atopic dermatitis with allergic, autoimmune, and cardiovascular comorbidities in US adults. Ann Allergy Asthma Immunol. 2018;121:604-12. 
18. Shalom G, Dreiher J, Kridin K, Horev A, Khoury R, Battat E, et al. Atopic dermatitis and the metabolic syndrome: a cross-sectional study of 1,16,816 patients. J Eur Acad Dermatol Venereol. 2019;33:1762-7.

19. Andersen YMF, Egeberg A, Gislason GH, Hansen PR, Skov L, Thyssen JP. Risk of myocardial infarction, ischemic stroke, and cardiovascular death in patients with atopic dermatitis. J Allergy Clin Immunol. 2016;138:310-2.

20. Andersen YMF, Egeberg A, Skov L, Thyssen JP. Comorbidities of atopic dermatitis: beyond rhinitis and asthma. Curr Dermatol Rep. 2017;6:35-41.

21. KokW, Yew $Y$, Thng T. Comorbidities associated with severity of atopic dermatitis in young adult males: a National Cohort study. Acta Derm Venereol. 2019;99:652-6.

22. Silverberg I. Comorbidities and the impact of atopic dermatitis. Ann Allergy Asthma Immunol. 2019;123:144-51.

23. Ascott A, Mulick A, Yu AM, Prieto-Merino D, Schmidt M, Abuabara K, et al. Atopic eczema and major cardiovascular outcomes: a systematic review and meta-analysis of population-based studies. J Allergy Clin Immunol. 2019;143:1821-9.

24. Drucker AM, Harvey PJ. Atopic dermatitis and cardiovascular disease: What are the clinical implications? J Allergy Clin Immunol. 2019;143:1736-8

25. Ivert $L$, Johansson $E$, Dal H, Lindelöf B, Wahlgren C, Bradley M. Association between atopic dermatitis and cardiovascular disease: a nationwide register-based case-control study from Sweden. Acta Derm Venereol. 2019:99:865-70.
26. Su VYF, Chen TJ, Yeh CM, Chou KT, Hung MH, Chu SY, et al. Atopic dermatitis and risk of ischemic stroke: a nationwide population-based study. Ann Med. 2014;46:84-9.

27. Brunner PM, Suárez-Fariñas M, He H, Malik K, Wen HC, Gonzalez J, et al. The atopic dermatitis blood signature is characterized by increases in inflammatory and cardiovascular risk proteins. Sci Rep. 2017;7:8707.

28. He H, Li R, Choi S, Zhou L, Pavel A, Estrada YD, et al. Increased cardiovascular and atherosclerosis markers in blood of older patients with atopic dermatitis. Ann Allergy Asthma Immunol. 2020;124:70-8.

29. Thyssen JP, Skov L, Hamann CR, Gislason GH, Egeberg A. Assessment of major comorbidities in adults with atopic dermatitis using the Charlson comorbidity index. J Am Acad Dermatol. 2017;76:1088-92.

30. Andersen YMF, Egeberg A, Hamann CR, Skov L, Gislason GH, Skaaby $T$, et al. Poor agreement in questionnaire-based diagnostic criteria for adult atopic dermatitis is a challenge when examining cardiovascular comorbidity. Allergy. 2018;73:923-31.

\section{Publisher's Note}

Springer Nature remains neutral with regard to jurisdictional claims in published maps and institutional affiliations.
Ready to submit your research? Choose BMC and benefit from:

- fast, convenient online submission

- thorough peer review by experienced researchers in your field

- rapid publication on acceptance

- support for research data, including large and complex data types

- gold Open Access which fosters wider collaboration and increased citations

- maximum visibility for your research: over $100 \mathrm{M}$ website views per year

At BMC, research is always in progress.

Learn more biomedcentral.com/submissions 